\title{
Nota de Apresentação dos Editores ${ }^{1}$
}

Temos o prazer de apresentar ao público leitor esta edição especial do Boletim de Análise Politico-Institucional (Bapi) sobre o tema Políticas Públicas Baseadas em Evidências (PPBEs). Este número integra a pesquisa "O que Informa as Políticas Públicas Federais: o uso e o não uso de evidências pela burocracia federal brasileira”, coordenada pela Diretoria de Estudos e Políticas do Estado, das Instituiçóes e da Democracia (Diest) do Ipea, e que envolve um esforço conjunto do Ipea, da Escola Nacional de Administração Pública (Enap), da Companhia de Planejamento do Distrito Federal (Codeplan) e do Institute of Development Studies (IDS). Vários dos artigos componentes desta ediçâao são assinados por nossos parceiros de pesquisa. ${ }^{2}$

Como é esperado - e, pela natureza do Bapi -, até desejável, os artigos reunidos apresentam-se em diferentes estágios de amadurecimento, recorrendo a múltiplas estratégias metodológicas. Algumas contribuiçôes são eminentemente teórico-conceituais, outras são estudos de caso em andamento ou finalizados, outras são exploraçóes iniciais do campo de pesquisa, outras lançam novos olhares sobre bases de dados e agendas de pesquisa consolidadas, mas que ainda não haviam sido tomadas sob a perspectiva da produçáo de evidências. Desse modo, esta edição contou com a contribuiçáo de variadas perspectivas analíticas, unificadas pelo intuito de se investigar o uso ou não de evidências em políticas públicas.

Tradicionalmente, as PPBEs são vistas como uma abordagem, um movimento, ou até mesmo um paradigma em políticas públicas, que "ajuda na tomada de decisōes bem informadas em políticas, programas e projetos públicos, colocando as melhores evidências de pesquisas disponíveis no coração do desenvolvimento e implementação das políticas públicas" (Davies, 2004, p. 3). Trata-se, portanto, de um modo de conceber e praticar políticas públicas, baseado no princípio de que as evidências de pesquisas científicas devem guiar as decisóes das autoridades de políticas - os chamados policymakers.

Não obstante a aparente singeleza da definição anterior, é grande a complexidade do assunto. A literatura mostra marcadas diferenças nas formas como as PPBEs são apropriadas entre áreas de políticas (saúde, macroeconomia, educação, justiça etc.), grupos de países (Estados Unidos, comunidade britânica, América Latina etc.), segmentos das burocracias públicas e atores sociais (policymakers, policy analysts, grupos de advocacy, públicos-alvo etc.), só para citar alguns planos de análise. Acompanhando essa diversidade de abordagens, o próprio conceito de evidência náo pode ser restrito a um único tipo, digamos, às evidências fornecidas por pesquisas científicas. Um dos tópicos para que a literatura parece convergir é o da complexidade dos processos decisórios em políticas públicas, acarretando o fato de que as evidências científicas, conquanto importantes para informar as decisôes, não são os únicos elementos a serem considerados nos contextos decisórios dos policymakers, contextos estes muitas vezes marcados pela urgência e pelo cálculo político.

Muito pouco ainda se tem investigado, menos ainda no Brasil, as formas como as evidências científicas interagem com outros instrumentos informativos na exuberante floresta dos contextos decisórios

1. DOl: http://dx.doi.org/10.38116/bapi24notaedi

2. Os editores convidados deste Bapi agradecem a importante colaboração de Bruno Gontyjo do Couto nos trâmites e na facilitação da interlocução entre editores, autores e pareceristas. 
de políticas públicas. O policymaker brasileiro toma suas decisões enquadrado numa moldura contextual, que delimita um pano de fundo em que se entretecem vários fatores de ordem epistemológica, política, histórica, cultural e institucional, entre outras. No entanto, ainda pouco sabemos sobre as feiçôes concretas que esse pano de fundo assume em nosso país, bem como sobre a definição daquela moldura. Por isso, a complexidade dos contextos decisórios na administração pública federal brasileira e o papel das evidências aí desempenhado foram escolhidos como o motivo condutor desta edição do Bapi.

Os doze artigos que se seguem procuram ilustrar os papéis desempenhados pelas evidências nas decisóes públicas, em várias áreas temáticas (saúde, governo digital, habitação, segurança pública, administração da justiça, programas sociais), nos três poderes da República e em distintos segmentos da burocracia pública (comissóes parlamentares, órgãos de controle, gestores de programas, diretoria de agência reguladora etc.). A diversidade teórica e metodológica também é apreciável nos trabalhos publicados nesta edição do boletim, assim como a multiplicidade de formaçóes, áreas de conhecimento e instituiçóes às quais pertencem as autoras e os autores. Nesta Nota de apresentação dos editores, os artigos foram reunidos em quatro tópicos, a saber: i) fundamentos, conceitos e modelo de análise; ii) estudos de casos de políticas; iii) usos de evidências pelos órgáos de controle; e iv) usos de evidências pelos poderes Legislativo e Judiciário.

\section{Fundamentos, conceitos e modelo de análise}

Nossa publicação começa com o estabelecimento de um marco conceitual, teórico e metodológico. Este desafio é enfrentado por Maurício Mota Saboya Pinheiro, o autor do artigo Politicas públicas baseadas em evidências: uma avaliação crítica. $\mathrm{O}$ texto discute o conceito de evidência em políticas públicas e, por meio de um modelo caracterizado como moderado, faz uma crítica a uma visáo tradicional da abordagem das PPBEs.

Pinheiro propõe um método de análise conceitual das evidências amparado sobre três pilares: i) história do conceito; ii) explicitação de pressupostos epistemológicos dos modelos que dão sentido ao conceito de evidência; e iii) explicitação dos contextos de uso e aplicaçáo do conceito em pauta. Em seguida, propóe-se um modelo moderado - uma via media entre o racionalismo e o construcionismo -, procurando conciliar a complexidade do real e a racionalidade de sua explicação, bem como harmonizar o uso de evidências científicas nas políticas públicas com uma visão crítica e contextualizada desse uso. O modelo moderado mergulha suas raízes especulativas na teoria da complexidade, no realismo crítico, no pragmatismo filosófico e na filosofia do senso comum. O texto também enfatiza um pano de fundo ontológico delimitado por uma moldura contextual em que se dão as decisóes dos policymakers. Nesse pano de fundo, fatores epistemológicos, políticos e institucionais lato sensu se entrelaçam inextricavelmente. Por isso, as evidências usadas na tomada de decisóes em políticas públicas não podem ser definidas de maneira estreita, sem privilégio a priori às evidências científicas - as quais, muitas vezes, são colocadas no topo de uma hierarquia rígida de qualidade -, tampouco as ignorando por completo. Por fim, as evidências usadas em políticas públicas são concebidas como quaisquer instrumentos informativos, mobilizados pelos policymakers e outros atores sociais interessados, empregados nas decisóes de políticas públicas, dada uma determinada moldura contextual.

O trabalho de Pinheiro se alinha com uma crescente literatura que procura, a partir de um forte embasamento teórico-filosófico, encontrar alternativas viáveis ao uso de evidências em políticas públicas e, ao mesmo tempo, evitar certas perspectivas simplistas, idealizadas ou incoerentes das PPBEs. Finalmente, 
o artigo é promissor como ponto de partida para a elaboração de futuras pesquisas devotadas à construção de um sistema de governança para o uso de evidências nas políticas públicas brasileiras.

Dando seguimento a essa reflexão analítica, mas com uma preocupação mais aplicada ao caso brasileiro, o segundo artigo leva o título de Análise de politicas públicas e uso de evidências pelas burocracias: proposta de um modelo analítico para exploração das fontes que informam as políticas públicas no caso brasileiro. Assinado por Natália Massaco Koga, Pedro Lucas de Moura Palotti, Maricilene Isaira Baia do Nascimento e Bruno Gontyjo do Couto, o trabalho busca construir um modelo analítico capaz de orientar uma pesquisa empírica sobre o uso de evidências científicas para subsidiar as decisóes de políticas públicas federais no Brasil.

A literatura percorrida pelos autores vai desde o ramo da chamada análise de política (policy analysis) até a da capacidade de produção de políticas (policy capacity), passando também pela literatura de policy work (trabalho na política pública). Esta última parece destacar mais o aspecto da "arte" das políticas públicas do que o seu aspecto "ciência". Essa arte da política envolve a mobilizaçáo de um conjunto de habilidades e recursos dos produtores da política e de sua organizaçáo, habilidades essas que não se restringem à capacidade analítica, embora com esta interaja. Duas vertentes adicionais de estudos empíricos balizam a construção do modelo analítico de uso das evidências pela burocracia federal no Brasil: i) estudos voltados para os condicionantes do uso das evidências stricto sensu; e ii) estudos voltados para o mapeamento das fontes de informação usadas pelas burocracias. Além disso, interessados que estão num entendimento abrangente do uso do conhecimento nas políticas públicas, Koga, Palotti, Nascimento e Couto debruçam-se também sobre estudos empíricos em países que não têm sido táo influenciados por esse movimento, como os países nórdicos e anglo-saxóes. Nesse sentido, algumas pesquisas para o caso brasileiro já revelaram uma participaçáo muito importante de fontes normativas (leis, normas) e de recomendaçóes de órgãos de controle na produção de políticas públicas federais no Brasil. Logo, não pode faltar também no modelo analítico um tratamento especial às fontes de informaçóes normativas e técnicas. Finalmente, o modelo analítico proposto destaca três dimensóes de análise: $i$ ) individual (escolaridade, treinamento, funçôes, valores etc.); ii) organizacional; e iii) relacional (comunicação e interação entre as "duas comunidades", a acadêmica e a de burocratas).

Um aspecto importante, no que tange à construçáo de um modelo analítico para o estudo das PPBEs no Brasil, é que aquele deve contemplar um espectro relativamente amplo de possibilidades de usos e fontes de evidências pelos burocratas federais brasileiros, capaz de abarcar as especificidades e - por que náo dizer? - as inovaçóes do caso brasileiro. Os policymakers singularizam-se por seus valores, sua cultura, sua história e seus ambientes institucionais próprios. Por isso, na construção de um modelo analítico para o Brasil, deve-se evitar o viés de fazê-lo à imagem e semelhança de algo já aplicado e consolidado em países onde prevalece o mainstream das PPBEs, e onde há preocupaçóes específicas e contextualizadas de aumentar a absorção de conhecimento de pesquisas científicas em certas áreas de políticas públicas. Enfim, o modelo brasileiro não deve ser uma espécie de "camisa de força” importada que limite as possibilidades analíticas de um estudo adequado à realidade brasileira. A diversidade de fontes e perspectivas usadas por Koga, Palotti, Nascimento e Couto na construção do seu modelo analítico mostra que os autores não caíram nessa armadilha.

Avançando um pouco mais na realidade brasileira, mas ainda em sobrevoo panorâmico, encontra-se o artigo de Tatiana Lemos Sandim e Daienne Amaral Machado, o terceiro desta série, intitulado $O$ paradigma das políticas públicas baseadas em evidências na gestão pública brasileira: 
uma análise das publicaçôes acadêmicas. Como a administração pública no Brasil tem incorporado elementos preconizados pela abordagem das PPBEs? Como essa abordagem se "afeiçoou" na prática da administração pública em solo nacional? Estas são perguntas de fundo que motivam a pesquisa, ainda em andamento, cujos resultados preliminares são apresentados no artigo. Este objetiva fazer uma revisão da literatura sobre a aplicação da abordagem das PPBEs no Brasil, em suas várias modalidades e áreas governamentais.

Inicialmente, o que mais salta aos olhos é que há um pequeno número de artigos que discutem a relação entre a administração pública brasileira e o uso de evidências, revelando uma produção acadêmica pouca expressiva numericamente e a ausência de análise sobre as iniciativas governamentais visando ao fomento do uso sistemático de evidências criadas nos últimos anos. No apoucado conhecimento disponível sobre as PPBEs no Brasil, destaca-se algum material produzido para as políticas de saúde. Em consonância com a linha bridging the gap ${ }^{3}$ da literatura internacional, a tônica aqui é a necessidade de cobrir lacunas entre o conhecimento produzido na academia e as decisóes de políticas públicas, especificamente no que concerne à “'tradução' da linguagem acadêmica e (...) disseminação de sua produção para alcançar gestores públicos”(p. 45). Em outras áreas de política, fora a de saúde, parece predominar uma discussão crítica sobre o uso de evidências nas políticas públicas, sobretudo inspirada por uma visão construcionista ${ }^{4}$ da realidade social.

Ressalta-se, na revisão bibliográfica feita por Sandim e Machado, a complexidade do processo de tomada de decisóes em políticas públicas, em que se chocam diversas forças sociais representadas por stakeholders públicos ou de fora do Estado. Nesse diapasão, hierarquias rígidas de evidências são problematizadas e o risco de se reificarem as evidências quantitativas é denunciado (Campos, Onocko-Campos e Barrio, 2013). A visão da ciência como uma narrativa apartada da política é rejeitada, assim como se destaca a importância da visão dos gestores sobre o papel das evidências científicas como elementos justificadores, no nível da persuasão pública, de certas medidas de políticas (Carneiro e Danton, 2012). Portanto, com a possível exceção de trabalhos relativos à área de saúde, a maior parte da reflexão produzida no país sobre as PPBEs parece ser de crítica a essa abordagem, ou, pelo menos, a uma visão tradicional dela, a qual propugna um uso mais intenso e instrumental das evidências científicas, como uma forma de melhoria da qualidade das decisões em todas as áreas de políticas públicas.

\section{Estudos de casos de políticas}

A partir do quarto artigo, Uso de evidências cientificas na avaliação da incorporação de tecnologias em saúde no SUS: uma análise preliminar, escrito por Fabiola Sulpino Vieira, Luciana Mendes Santos Servo e Sergio Francisco Piola, inicia-se uma série de estudos de casos que pretendem lançar luz sobre vários aspectos do uso das evidências nas multifacetadas situaçóes em que os agentes públicos na administração federal brasileira tomam suas decisões.

Nesse artigo, com base em uma amostra de decisões da Comissão Nacional de Incorporação de Tecnologias no Sistema Único de Saúde (Conitec), analisa-se a qualidade das evidências usadas na avaliação de intervençóes terapêuticas. Constata-se que a maioria das decisóes foi informada por evidências científicas que indicam nível de confiança de moderado a alto no efeito estimado dessas intervenções.

3. Isto é, a preocupação de "abrir caminho" ou "cobrir a lacuna" entre os produtores de evidências científicas (acadêmicos, técnicos de pesquisa etc.) e os usuários dessas evidências nas políticas públicas.

4. Em termos gerais, o construcionismo reza que toda a realidade humano-social é "construída" cultural, histórica e socialmente. Isso inclui realidades como línguas, religiões, leis, normas sociais, valores, moral, sexualidade, ideias etc. 
Entretanto, houve decisóes favoráveis à incorporação da tecnologia avaliada com base em evidências consideradas insuficientes, o que revela que nem sempre é mantido um maior rigor quanto à qualidade das evidências. Por exemplo, verificam-se marcadas diferenças entre a qualidade das evidências usadas na avaliação de medicamentos para tratamento da atrofia muscular espinhal (qualidade mais baixa, com apenas um ensaio clínico randomizado - ECR) e da esclerose múltipla (mais alta, com cinco ECRs e uma revisão sistemática). O estudo também apura que as decisões da Conitec são sensíveis a consultas públicas e decisóes judiciais, como nos casos da adoção do medicamento Certolizumabe Pegol (CZP) para o tratamento da artrite psoríaca e das insulinas análogas para o tratamento da diabetes. Constatou-se também que as evidências econômicas (análises de custo-efetividade etc.) não são determinantes para as decisóes da comissão, a despeito de esse tipo de evidência estar previsto em lei e nas suas normas internas, e ter algum peso no subsídio às decisóes da Conitec (como no caso da adoção do CZP). Por fim, Vieira, Servo e Piola (p. 55) concluem:

houve avanços importantes quanto às ATS [avaliação de tecnologias em saúde] no SUS [Sistema Único de Saúde] nos últimos anos. Entretanto, ainda se observam desconformidades significativas quanto às práticas recomendadas para um processo de ATS robusto e confiável, conforme sinaliza a presente análise realizada sobre o nível das evidências.

Portanto, Vieira, Servo e Piola constatam "desconformidades" em parte das decisóes da Conitec, no que se refere à regulamentação interna dessa comissão, em termos de qualidade das evidências utilizadas. "Evidências" aqui significam "evidências científicas", que são aquelas produzidas por métodos sistemáticos e replicáveis. Na maior parte da literatura sobre políticas de saúde, à qual pertence o artigo, as revisóes sistemáticas de ECRs ocupam, especialmente no caso de medicamentos, o topo da hierarquia de qualidade, seguidos pelos ECRs. De um nível de qualidade baixo ou muito baixo, são considerados, por exemplo, estudos observacionais ou estudos de casos. Entretanto, para alguns tipos de intervençốes, como medicamentos utilizados no tratamento de doenças raras ou de intoxicaçóes, é praticamente impossível a realização de ECRs. Por isso, toleram-se - e até certo ponto justificam-se - decisóes de políticas baseadas em evidências de "menor qualidade". Por fim, os autores recomendam futuros estudos que possam incorporar na análise outros fatores que impactam o nível de evidências no processo de ATS, como a cooptação de membros da comissão ou policymakers da saúde por agentes do complexo econômico-industrial.

Ainda contemplando a área da saúde, Milena Karla Soares é autora do quinto artigo desta edição do Bapi. O trabalho intitula-se Ignorância e politicas públicas: a regulação de cannabis medicinal no Brasil. O estudo versa especificamente sobre a regulação, pela Agência Nacional de Vigilância Sanitária (Anvisa), do cultivo e uso medicinal da cannabis. A autora analisou seis votos de diretores da Anvisa a respeito de questôes específicas envolvendo a regulação do uso terapêutico da cannabis em solo nacional. As questôes foram as seguintes: i) a cannabis apresenta propriedades terapêuticas?; ii) os produtos importados à base de cannabis apresentam segurança, eficácia e qualidade?; iii) a Anvisa tem competência para regular o plantio da cannabis?; e iv) a regulaçáo do plantio reduzirá o custo dos medicamentos à base de cannabis? $\mathrm{O}$ artigo conclui pela recomendação do aprofundamento do debate técnico, ao menos na questão da regulação do plantio. Ademais, o "mapeamento dos pontos de ignorância relevantes, [a] reflexão sobre quais ignorâncias são superáveis, e [a] pactuação de critérios para aceitação de conhecimento como válido" (p. 66) seriam elementos de uma gestáo ou governança do conhecimento (ou ignorância), que pudesse ao menos mitigar as "consequências imprevistas" decorrentes dos (ultimamente frequentes) "atropelos" das decisóes da Anvisa por decisões judiciais. 
A perspectiva do trabalho de Soares é sui generis, pois trata não diretamente do uso de evidências, mas, por assim dizer, do "reverso da medalha": o papel da ignorância, definida pela autora como "ausência de conhecimento” nas decisões da política pública em questão. Pelo menos desde Sócrates, sabe-se que quanto mais alguém acumula conhecimento, mais tem consciência da própria ignorância, pois, em qualquer área do saber e, em particular, no processo de decisão pública, o fluxo de novas perguntas tende a ultrapassar o estoque de coisas sabidas. Nesse sentido, a autora argumenta que "a ignorância pode ser um fator tão decisivo quanto o conhecimento nas políticas públicas” (p. 57). Quem sabe, as situaçóes de relativa ignorância sejam até mais numerosas nas políticas públicas do que aquelas em que predomina o conhecimento, seja este pautado por evidências científicas ou, pelo menos, por informações confiáveis. Portanto, não surpreende o fato de que "atores podem fazer uso estratégico da ignorância para promover interesses, bem como manter ou subverter o ordenamento sociopolítico” (McGoey, 2012).

O texto de Soares aborda questóes interessantes e que estão no coração do processo decisório dos policymakers, pois mostra que os instrumentos de decisão podem ser tanto as informaçóes quanto a ausência delas (ignorância). No caso em questão, as primeiras podem incluir conhecimentos e evidências científicos, mas não apenas desse tipo - haja vista que a ignorância sobre os efeitos terapêuticos da cannabis foi relativizada por um diretor da Anvisa, que alegou a existência de conhecimento não científico, produzido por usuários isolados, acerca desse potencial terapêutico. A análise de uma amostra de votos dos diretores da Anvisa, acerca de seus processos deliberativos em torno de questóes sobre a regulação do uso, cultivo, comercializaçáo etc. da cannabis para fins medicinais, mostra que, assim como o conhecimento científico, a ignorância também pode suscitar posicionamentos e açóes divergentes da parte de um único corpo deliberativo. As lacunas de conhecimento muitas vezes são preenchidas pelas crenças, valores e princípios dos atores, motivando certas deliberaçóes - por exemplo, na questão sobre a existência de propriedades terapêuticas da cannabis. A própria existência ou não de conhecimento sobre uma questão, se esse conhecimento não for consensual e assentado entre os atores, pode ser motivo de divergência entre os membros do corpo deliberativo, dadas as suas diversas visóes de mundo prévias. Um exemplo disso ocorre na questáo sobre o impacto da regulação no custo de produção dos medicamentos à base de cannabis, visto quase como autoevidente por um diretor da Anvisa, ao passo que outros declararam ignorância sobre essa questão.

Diz-se, com frequência, que há muitos fatores que afetam as decisóes dos policymakers para além das evidências (científicas ou não), e que estes têm de decidir num reduzido arco temporal, premidos pela urgência de certas questóes, independentemente de haver informaçóes de qualidade que sustentem essas decisóes. Ora, nesse artigo, a autora traz mais um complicador a esse quadro: a própria ignorância pode ser um fator motivador de decisóes, e um elemento passível de instrumentalizaçáo no complicado "jogo de xadrez" do poder político de que tomam parte os stakeholders de uma política pública.

Deixando a saúde, mas ainda na grande área da política social, Natália Massaco Koga, Rafael Viana e Ivan da Costa Marques assinam o sexto artigo desta edição, que leva o título de Usos e significados do Cadastro Único para os programas sociais federais: fonte de evidências técnico-instrumentais ou retratos técnico-político-sociais? Os autores investigam, via entrevistas, os "usos, sentidos e valores" do Cadastro Único (Cadúnico), como instrumento informativo de programas sociais federais, sob a óptica dos gestores desses programas. Analisam-se os múltiplos usos do Cadúnico, bem como as mudanças de perspectivas e significados para a ação pública de combate à pobreza, trazidas por esse instrumento. 
Além de seus usos meramente instrumentais, como fonte de evidências para o apoio às decisóes das políticas sociais, o Cadúnico também se presta a usos que interagem com a própria semântica da linguagem sobre a pobreza. O trabalho de Koga, Viana e Marques mostra que novos significados nessa área são construídos interativamente, a partir de processos e rotinas internos ao cadastro, como a operacionalizaçáo de critérios de inclusão, cruzamento de bases de dados e outros. Nesse sentido, esse instrumento teria servido para estabilizar "conceitos fulcrais para a implementação das políticas sociais como pobreza, renda, família, domicílio" (p. 74). A multiplicidade de seus usos conduz a vários resultados, alguns intencionais ou desejáveis, como o fornecimento de evidências para os gestores defenderem os "interesses do programa”, uma melhor compreensão da realidade das famílias cadastradas, a iluminação de novas questóes sociais, mas outros muitas vezes não previstos ou mesmo percebidos, como a estigmatização da pobreza, a disseminação da lógica da desconfiança e controle e o aumento do distanciamento entre Estado e cidadão. Os autores concluem que o instrumento precisa ter o seu processo aperfeiçoado, introduzindo um uso que ainda se encontra praticamente ausente: a voz dos próprios inscritos do cadastro.

Nesse artigo, Koga, Viana e Marques destacam que o uso do Cadúnico não é neutro do ponto de vista dos significados e valores das açôes públicas na área dos programas sociais. Em outras palavras, entre os múltiplos usos do cadastro, encontra-se um conjunto que acarreta a construção, estabilização e modificação de conceitos usados em diversas narrativas, tanto de policymakers quanto de outros atores sociais. Interessante notar que essa reconstrução semântica pode se dar em meio a um processo de operacionalização do próprio instrumento que, em suas rotinas de cruzamento de bases de dados, delimitação de critérios de inclusão e outras decisões operacionais, acaba por "fixar" o âmbito de aplicação de certos conceitos-chave aos programas sociais (pobreza, família e outros). Esse processo contínuo de construção e reconstrução conceitual - que em parte se materializa num conjunto de decisóes analíticas, operacionais e gerenciais dos burocratas - reflete, em algum grau e, de certa forma, disputas entre atores sociais. Assim, o Cadúnico é, ao mesmo tempo, um instrumento técnico-informativo que serve aos policymakers para a tomada de decisóes de políticas sociais e um instrumento político lato sensu, usado por vários atores sociais na construçáo de seus conceitos, significados, narrativas e identidades.

Pedro Lucas de Moura Palotti, Fernando de Barros Filgueiras e Maricilene Isaira Baia do Nascimento são autores do sétimo artigo, Policy design e múltiplas evidências: proposta analítica da dinâmica da política de transformação digital dos serviços públicos da administração pública federal brasileira. Os autores buscam construir um quadro analítico para o uso de evidências, aplicável ao projeto de uma política de transformação digital nos serviços públicos federais brasileiros. Essa política visa automatizar a entrega, pelo governo federal, de certos serviços públicos a cidadãos e empresas, disponibilizando-lhes um conjunto de ferramentas digitais capazes de "aprendizado" (machine learning). Com isso, a política visa não só aumentar a prestação de serviços, mas também melhorar sua qualidade. Nesse sentido, a política de transformação digital pretende revolucionar a estrutura de governança dos serviços públicos.

Por sua vez, o uso de múltiplas evidências (conhecimentos e informaçôes) justifica-se pela complexidade da política de transformação digital, a qual envolve muitos atores, processos, instrumentos e interpretaçôes de várias ordens. Trata-se de uma multiplicidade de fontes, tipos e usos de evidências, bem como de seus papéis nas narrativas dos atores, em diferentes etapas do processo de política. As diversas interpretaçóes dos stakeholders sobre o que significa uma política de transformação digital para os serviços públicos estão frequentemente em disputa. 


\section{Usos de evidências pelos órgãos de controle}

Adentrando a área das atividades e políticas de controle, Marlos Moreira dos Santos, Bianca Alves Silveira e Eliane Ferreira da Rocha são os autores do oitavo artigo, Cartão Reforma: avaliação de políticas públicas através de evidências. O texto avalia o uso de evidências da parte dos auditores ou consultores da Controladoria-Geral da União (CGU), em seu trabalho de avaliação do Programa Cartão Reforma, especificamente no problema do deficit habitacional qualitativo. Náo se trata de uma avaliaçáo direta do programa, mas de uma espécie de meta-avaliação, sob a ótica dos processos de trabalho da CGU.

Santos, Silveira e Rocha narram uma divergência de entendimento entre a CGU e os gestores do programa em pauta a respeito da importância relativa de certos componentes do deficit habitacional e da consequente alocaçáo de recursos do programa a esses componentes. Apoiados sobre evidências de pesquisas da Fundação João Pinheiro (FJP) - que apontava a importância crucial do item "esgotamento sanitário" para o deficit habitacional -, a CGU contesta a decisão dos gestores do Cartão Reforma de destinarem metade dos recursos do programa ao item "conclusão habitacional". Os gestores, por sua vez, apoiam sua decisão em evidência fornecida pela própria FJP, que endossa a importância da depreciação das habitaçóes como um dos fatores da inadequação domiciliar, problema que deveria ser atacado com recursos destinados à execução de serviços de alvenaria, revestimentos, piso, pintura, entre outros serviços (item "conclusão habitacional"). O contra-argumento da CGU é que a depreciação habitacional não é mensurada e, por isso, não teria sua eventual redução computada nos índices de deficit habitacional qualitativo dos órgãos oficiais (Instituto Brasileiro de Geografia e Estatística - IBGE e Secretaria Nacional da Habitação - SNH), frustrando assim o cumprimento das metas do programa. Além disso, nessas condiçôes, a alocação de recursos proposta pelo gestor não atenderia a uma rigorosa análise custo-benefício.

A controvérsia entre a CGU e o gestor do Programa Cartão Reforma ilustra um embate de visóes e de interesses que não se restringe a divergências técnicas entre este ou aquele índice de deficit habitacional, esta ou aquela metodologia. Embora o gestor procurasse argumentar tecnicamente, baseando seu posicionamento em evidências aduzidas por uma fonte reconhecida por sua confiabilidade técnica (FJP), a CGU aponta deficiências metodológicas que desqualificam em parte a argumentação do gestor. Contudo, sob a superfície deste embate técnico, escondem-se disputas econômicas e políticas entre uma ampla gama de outros atores (os "parceiros", tais como empreiteiros, governadores, membros da sociedade civil etc.) interessados no Programa Cartão Reforma. Nesse sentido, uma conclusão importante do artigo de Santos, Silveira e Rocha (p. 100) é que

a adesão de parceiros, identificada no apoio e reforço dos parlamentares na elaboração da Lei do Cartão Reforma incorpora à narrativa política o uso de evidências, mas numa perspectiva distinta daquela da burocracia. Isso porque nem toda evidência é considerada para afetar o desenho da política. [Ou seja, há] (...) uma hierarquia de evidências que podem ser mais ou menos manipuladas conforme (...) [a] narrativa mais adequada para convencimento do público.

Portanto, nesse artigo, temos mais um exemplo de como o contexto decisório do policymaker, interagindo com outros stakeholders da política, pode afetar o uso das evidências. O estudo sugere que, no caso do Cartão Reforma, houve um uso seletivo e estratégico das evidências de pesquisas, em favor de uma narrativa e decisóes que acomodassem os interesses dos parceiros da política em questáo. Não cabe fazer juízos de valor sobre qual perspectiva (CGU ou gestor) é a mais correta; apenas se quer aqui destacar as disparidades nas perspectivas de uso das evidências, bem como nas formas de governança das evidências entre dois diferentes e relevantes atores. 
Complementando o exemplo de usos possíveis das evidências pela CGU na tomada de decisóes, figura o nono artigo deste boletim, Auditores internos da Controladoria-Geral da União: como atuam e que informaçóes utilizam, assinado por Tiago Chaves Oliveira e Wagner Brignol Menke. Como as preferências internas dos auditores da CGU, de caráter didático ou repressivo, se refletem no uso que estes fazem das evidências em suas auditorias? Esta é a pergunta central do artigo, que se serve de um survey e de entrevistas com aqueles auditores. Os principais resultados do trabalho podem ser elencados como segue: $i$ ) auditores com maior preferência por apuraçóes, isto é, com atuação mais repressiva, preferem a utilização de leis, decretos e normas, assim como fazem maior uso de dados governamentais; ii) artigos científicos são considerados de menor relevância aos auditores e, quando aplicáveis, têm maior uso como inspiração metodológica ou confirmação externa de dados; e iii) a seleção do tipo de fonte de informação a ser utilizada pelos auditores depende da maturidade da instituição e do setor avaliado. Os auditores entendem que, naquelas áreas com maior maturidade, há mais informaçôes disponíveis, e nas com menor maturidade, devem se basear em normativos e informaçóes fornecidas pela própria gestáo, uma vez que há escassez de fontes disponível.

O estudo de Oliveira e Menke revela várias especificidades interessantes do uso das informaçóes por auditores da CGU, entre elas, algumas já detectadas em outras pesquisas mais abrangentes sobre a burocracia brasileira (Enap, 2018) - por exemplo, um uso mais amplo de informaçóes normativas do que de resultados de pesquisas científicas. No caso dos auditores da CGU, um argumento é esboçado para justificar o relativamente baixo emprego de evidências científicas: a existência, em estudos acadêmicos, de vieses que poderiam comprometer a objetividade das auditorias. Requer-se um aprofundamento desse argumento, relacionando-o com o ethos profissional e com a cultura organizacional dos auditores da CGU.

\section{Usos de evidências pelos poderes Legislativo e Judiciário}

Heterogeneidade de preferências e o uso de evidências na Câmara dos Deputados é o décimo artigo desta edição do Bapi, escrito por Acir Almeida, e que inaugura um conjunto de análises inéditas da perspectiva do Poder Legislativo. O texto procura lançar luz sobre o uso "estratégico" de evidências nas tomadas de decisóes em políticas públicas, em sua fase legislativa. Para isso, o autor lança mão de certa literatura sobre economia da informação. Ele parte da proposição teórica de que "a qualidade da informação que embasa a recomendação da comissão [parlamentar] deve ser crescente na heterogeneidade das preferências” (p. 117) e procura testar essa hipótese para as comissóes da Câmara dos Deputados.

O critério usado por Almeida para mensurar a qualidade das informaçóes usadas nos pareceres das comissôes baseia-se na "verificabilidade da informação a respeito dos resultados esperados da política proposta” (p. 119), sendo a informação mais "verificável” aquela obtida de forma mais sistemática, exata e estatisticamente testada. Assim, o autor classifica os tipos de informaçóes usadas numa escala que vai de "muito baixa” (opinião pessoal) até "muito alta" (estudos sistemáticos de natureza causal). Essa classificação reflete, de alguma forma, a hierarquia clássica das evidências, adotada pela perspectiva tradicional das PPBEs.

$\mathrm{Na}$ amostra de pareceres analisada, que náo pode ser generalizada, pois não é representativa, a maioria esmagadora das informaçóes usada é de qualidade baixa ou muito baixa $(79,1 \%)$, e apenas 12,8\% são de qualidade alta ou muito alta. Finalmente, dois pontos são dignos de nota nas conclusôes do artigo de Almeida: i) a heterogeneidade das preferências e os conflitos de interesses políticos na Câmara não são necessariamente incompatíveis com decisôes "bem informadas", isto é, com o uso de informaçóes de boa qualidade nessas decisões; e ii) há uma relação entre a maneira como se organiza o contexto decisório e 
a qualidade das informaçóes utilizadas, de modo que "a correta identificação das condiçôes e incentivos que favorecem o uso da melhor evidência disponível requer que se compreenda melhor como funciona o processo decisório - sua organização, atores relevantes e motivaçóes - e qual o papel da informação para os tomadores de decisão" (p. 123).

O interessante trabalho de Almeida abre uma oportunidade de diálogo entre a abordagem das PPBEs e a teoria econômica da informação. Além disso, sugere, em algum grau, uma relação empírica entre o contexto decisório e a qualidade das evidências usadas nas decisóes de políticas públicas, sendo que essa qualidade pode ser, em tese, melhorada com alterações nas condições do processo decisório, inclusive, quando há maior conflito de interesses. Este último item, que pode constar numa agenda de futuras pesquisas sobre o tema, aponta para um elemento central do "modelo moderado", defendido no primeiro artigo desta edição: a moldura contextual no interior da qual se dão as decisóes dos policymakers. A definição dessa moldura, a especificação dos fatores que compóem o seu pano de fundo ontológico e a estrutura da decisão do agente são exemplos de questóes em aberto no estudo geral das PPBEs, mas que devem ser enfrentadas, a fim de se chegar a visóes mais realistas do uso das evidências em políticas públicas.

Ainda no plano de análise dos usos de evidências pelo Legislativo brasileiro, Helder Ferreira assina o trabalho Análise de qualidade de evidências científicas utilizadas em política pública: aplicação a documentos relativos à tramitaçáo do PL $n^{\circ} 3.722 / 2012$, que flexibiliza o controle de armas de fogo, o décimo primeiro desta série. $\mathrm{O}$ artigo procura avaliar a qualidade de evidências científicas utilizadas em documentos relativos à tramitação do PL no 3.722/2012, que "disciplina as normas sobre aquisiçáo, posse, porte e circulação de armas de fogo e muniçóes" (Brasil, 2012). Adota-se um conceito restritivo de evidência, igualando-o ao de evidência científica, e aplica-se, no exame da justificação apresentada no PL original, substitutivos e em votos em separado, uma adaptação da metodologia proposta por Lee et al. (2017) para revisão sistemática e avaliação da qualidade de evidências justamente para o contexto de políticas de controle de armas.

A regulamentação da aquisição, posse, porte e circulação de armas de fogo e muniçóes pelo cidadão comum é um exemplo daquelas "questóes perversas" (wicked issues), das quais já falavam Rittel e Webber (1973). Carregados de emoçóes, valores, princípios morais e ideologias, os debates públicos envolvendo questóes deste tipo tendem a ser altamente polarizados politicamente e não parecem passíveis de resolução exclusivamente por meio de evidências científicas. Algumas vezes, ao contrário, tais evidências até acirram as contendas em torno desses assuntos. Dito isto, o artigo de Ferreira tem o mérito de contribuir para o debate sobre a qualidade das evidências, ao operacionalizar uma metodologia que busca diferenciar melhores de piores evidências científicas, ou de evidências insuficientes, em um contexto de política pública.

Finalmente, como único representante de uma análise do uso de evidências nas políticas do Poder Judiciário, encontra-se o décimo segundo artigo, que é o trabalho de Maricilene Isaira Baia do Nascimento e Rebecca Neaera Abers intitulado "Sempre haverá o melhor e o pior": controvérsias, criatividade e enquadramentos interpretativos em torno das estatisticas de produtividade comparada dos atores e das organizaçóes judiciárias no Brasil. A partir de um estudo sobre a política de estatísticas de produtividade dos atores e organizaçóes judiciárias no Brasil, as autoras procuram mostrar que as evidências científicas podem revelar sua natureza política quando se trata de definir autoidentidades e propósitos dos atores envolvidos. Pressupóe-se que são os atores que interpretam e atribuem significados às fontes, aos usos, aos métodos, às técnicas etc. de obtenção de evidências (científicas e outras) para as políticas públicas. Além 
disso, as relações de poder entre os atores acarretam reinterpretações das evidências científicas (seus usos, métodos etc.), reconfigurando estruturalmente o significado e o simbolismo dessas evidências.

Um dos focos dessa reinterpretação é o Índice de Produtividade Comparada da Justiça (IPC-Jus), baseado na metodologia data envelopment analysis (DEA) (uma verdadeira inovação na área das políticas judiciárias domésticas), e que visava ser um instrumento de obtenção de evidências científicas para a mudança comportamental dos atores e organizaçóes judiciários no Brasil. A análise de Nascimento e Abers procura mostrar que os atores constroem discursos criativamente estratégicos para contornar os desconfortos institucionais que tais indicadores de produtividade comparada, via IPC-Jus, podem gerar.

Não obstante as altas expectativas do IPC-Jus em mudar o comportamento dos atores e das organizaçóes judiciárias nacionais, induzindo o sistema como um todo a um melhor desempenho, o uso deste índice, até o momento, parece não ter gerado os resultados esperados. Como todos os instrumentos analíticos de natureza matemática e estatística, o IPC-Jus reflete uma tensão fundamental, a saber: trata os atores, as pessoas e as organizaçóes reais como membros de conjuntos abstratos, desprovidos de particularidades, história, identidades. Trata-se da velha tensão entre o geral e o particular, entre o abstrato e o concreto. Quando subsumidos em modelos estatísticos, os atores particulares têm desconsideradas muitas de suas informaçốes (auto)definidoras. Aproveitando o gap gerado nessa tensão, os atores reinterpretam os próprios instrumentos estatísticos e o uso destes, visando apoiar certas narrativas em torno de identidades e propósitos desses atores, com o intuito final de promover seus interesses nas disputas de poder. Esse movimento reinterpretativo é chamado de "criatividade política" pelas autoras Nascimento e Abers. Logo, se é verdade que, em políticas públicas, as estatísticas - e, de modo mais geral, as evidências científicas - "jamais falam por si mesmas" (Pawson, 2002), entáo é por meio da criatividade política que as informaçóes ganham novos e inusitados significados no jogo de poder argumentativo (retórico) que se desenrola nos processos de políticas públicas.

Com isso, os editores agradecem ao público leitor, às autoras e aos autores, aos avaliadores e a toda a equipe do Bapi. Afinal, a comunidade Bapi é a responsável pelo sucesso desta publicação, nesses dez anos que se seguem à criação da Diest/Ipea, sendo o boletim um veículo de divulgação dos resultados das pesquisas desenvolvidas nessa diretoria.

\section{REFERÊNCIAS}

BRASIL. Projeto de Lei no 3.722/2012. Disciplina as normas sobre aquisição, posse, porte e circulação de armas de fogo e munições, cominando penalidades e dando providências correlatas. Brasília: Câmara dos Deputados, 2012.

CAMPOS, G. W. de S.; ONOCKO-CAMPOS, R. T.; BARRIO, L. R. del. Políticas e práticas em saúde mental: as evidências em questão. Ciência e Saúde Coletiva, v. 18, n. 10, p. 2.797-2.805, out. 2013.

CARNEIRO, M. J.; DANTON, T. Agricultura e biodiversidade nas ciências sociais brasileiras: alimentando a comunicação entre ciência e políticas públicas. Sociologias, v. 14, n. 30, p. 252-289, maio 2012.

DAVIES, P. Is evidence-based government possible? London: Jerry Lee Lecture, 2004. 
ENAP - ESCOLA NACIONAL DE ADMINISTRAÇÃO PÚBLICA. Capacidades estatais para produçáo de políticas públicas: resultados do survey sobre serviço civil no Brasil. Brasília: Enap, 2018. LEE, L. et al. Firearms laws and firearm homicides: a systematic review. Jama Internal Medicine, p. 106-199, 2017. Disponível em: <https://www.researchgate.net/publication/310317015_Firearm_ Laws_and_Firearm_Homicides_A_Systematic_Review>. Acesso em: 1odez. 2019.

MCGOEY, L. Strategic unknowns: towards a sociology of ignorance. Economy and Society, v. 41, n. 1, p. 1-16, 2012.

PAWSON, R. Evidence-based policy: in search of a method. Evaluation, v. 8, n. 2, p. 157-181, 2002.

RITTEL, H. W. J.; WEBBER, M. M. Dilemmas in a general theory of planning. Policy Sciences, v. 4, n. 2, p. 155-169, 1973.

\section{BIBLIOGRAFIA COMPLEMENTAR}

PETTICREW, M.; ROBERTS, H. Systematic reviews in the social sciences: a practical guide. Malden: Blackwell Publishing, 2006. 